\title{
Effect of storage method and extender osmolality in the quality of cryopreserved epididymal ram spermatozoa
}

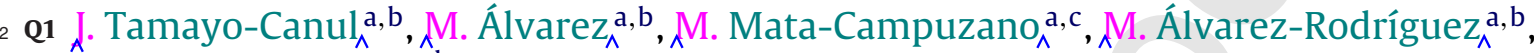

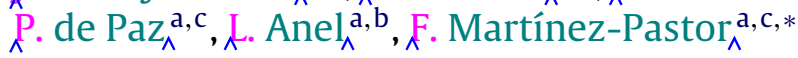 \\ a ITRA-ULE, INDEGSAL, University of León, 24071, León, Spain \\ b Animal Reproduction and Obstetrics, University of León, 24071, León, Spain \\ c Molecular Biology, University of León, 24071, León, Spain
}

\section{A R T I C L E I N F O}

\section{Article history:}

Received 28 June 2011

Received in revised form 8 November 2011

Accepted 12 November 2011

Available online $\mathrm{xxx}$

\section{Keywords:}

Ram

Extender

Osmolality

Sperm quality

Cryopreservation

\begin{abstract}
A B S T R A C T
Post-mortem sperm recovery and cryopreservation could be a complement to germplasm banking in sheep, especially for endangered breeds. This study is an attempt to identify factors for improving the success of cryopreserving ram epididymal spermatozoa, considering the decrease of sperm quality with post-mortem time. Epididymal spermatozoa from 9 rams were kept at $5{ }^{\circ} \mathrm{C}$ using three storage methods: within the epididymes, undiluted sperm mass, and diluted in extenders of different osmolality (TES-Tris-fructose at 320, 370 or $420 \mathrm{mOsm} / \mathrm{kg}, 20 \%$ egg yolk, $8 \%$ glycerol). At $0,24,48$ and $72 \hat{\mathrm{h}}$, spermatozoa were cryopreserved using each extender. Samples were analyzed before and after cryopreservation by CASA (motility) and flow cytometry (viability and acrosomal status). Post-mortem time decreased pre-freezing and post-thawing sperm quality. Some storage $\times$ extender combinations improved the effect of post-mortem time on sperm quality. Both epididymis storage combined with the 420 extender, and storing the spermatozoa diluted in the 320 extender improved post-thawing quality, especially at long post-mortem times. Storing the spermatozoa diluted in the 370 extender was detrimental for the acrosomal status. These findings have practical applications. The simplest storage method (within the epididymes) seems to be adequate if hyperosmotic extenders were used for freezing. An alternative method could be storing the spermatozoa diluted in a hypoosmotic extender. These recommendations are limited to the osmolalities tested in this study ( $420 \mathrm{mOsm} / \mathrm{kg}$ and $320 \mathrm{mOsm} / \mathrm{kg}$ ); other osmolalities should be tested.
\end{abstract}

(c) 2011 Published by Elsevier B.V.

\section{Introduction}

Artificial insemination in domestic animals relies almost exclusively on semen obtained by ejaculation (Anel et al., 2003). This is the case of the sheep, most of the doses being obtained by artificial vagina or electroejaculation (Anel et al., 2006). Nevertheless, post-mortem collection

Q2 * Corresponding a्रuthor at: Molecular Biology, University of León, 24071, León, Spain. Tel.: +34 9872915679.

E-mail address: felipe.martinez@unileon.es (F. Martínez-Pastor). could be useful, in the event that a genetically interesting male dies accidentally or must be culled (disease-carriers, physical defects, illness, etc.) (Ehling et al., 2006). For instance, our research group is working with two dairy breeds in Northwest Spain, Churra and Assaf 143,000 and 153,763 females, respectively, registered in breeding programs), whose genetic improvement programs include the use of post-mortem recovered spermatozoa.

There are many successful reports of collection and cryopreservation of epididymal spermatozoa (buffalo: Lambrechts et al., 1999; dog: Hewitt et al., 2001; ram: Kaabi et al., 2003; boar: Suzuki and Nagai, 2003; red 
deer: Comizzoli et al., 2001, Soler et al., 2005, MartinezPastor et al., 2006a; Spanish ibex: Santiago-Moreno et al., 2006; brown bear: Anel et al., 2011). Ideally, epididymal spermatozoa should be immediately extended and cryopreserved or used for insemination. However, dead males may not be promptly found, genitalia may need to be transported to another facility for processing, or immediate use may not be possible. Kaabi et al. (2003), stored ram epididymides at $5^{\circ} \mathrm{C}$, finding good sperm viability up to $48 \mathrm{~h}$ post-mortem, although fertility declined. Using cryopreserved epididymal spermatozoa from the Assaf breed, our group achieved a fertility of $52.8 \%$ if frozen before $2 \mathrm{~h}$ post-mortem (1054 intrauterine inseminations, unpublished results), similar to cryopreserved ejaculated semen (52.4\% in Churra breed; Anel et al., 2003). However, fertility decreased to $46 \%$ for samples frozen $24 \mathrm{~h}$ post-mortem. Moreover, Martins et al. (2009) showed that bull epididymal spermatozoa maintained an acceptable quality up to $48 \mathrm{~h}$, but fertility (embryo production by IVF) was reduced as soon as $24 \mathrm{~h}$ post-mortem. Martinez-Pastor et al. (2005b) found that the quality of epididymal spermatozoa from red deer decreased after the first two days post-mortem. Few studies have analyzed the effect of post-mortem time on the cryopreservation of epididymal spermatozoa. Soler et al. (2005) showed that post-thawing quality was well preserved up to $48 \mathrm{~h}$ post-mortem, and Fernández-Santos et al. (2009b) suggested that post-thawing sperm quality could be acceptable up to $96 \mathrm{~h}$ post-mortem. Nevertheless, Soler and Garde (2003) showed that the fertility of fresh epididymal spermatozoa (heterologous penetration test) decreased after $12 \mathrm{~h}$ post-mortem.

In an attempt to reduce the effect of post-mortem time on the post-thawing quality of ram epididymal spermatozoa, we have aimed at testing different storage methods and extenders. Few studies have focused on comparing storage methods for epididymal spermatozoa (TamayoCanul et al., 2011), and there are no reports on their effects on post-thawing quality. Maintaining the spermatozoa in the cauda epididymis have yielded acceptable results in previous studies (Lambrechts et al., 1999; Kaabi et al., 2003; Martinez-Pastor et al., 2005b, 2006a; Soler et al., 2005; Anel et al., 2011), but it submits the spermatozoa to a changing environment: disruption of the epididymal tissue (Songsasen et al., 1998), changes in osmolality and pH (Martinez-Pastor et al., 2005b) and changes in components of the epididymal fluid (Jones, 2004). A solution could be storing the sperm mass outside the epididymis ${ }_{\wedge}$ with or without extension. However, spermatozoa are submitted to a higher oxygen pressure outside the epididymis, and the blood and debris concomitant to the extraction could exert a negative effect (Martinez-Pastor et al., 2006a). Diluting the sperm mass immediately after collection with a buffered media containing protective substances (egg yolk) might help protecting spermatozoa, but it might convey disadvantages (osmotic shock, modifications of sperm membrane by egg yolk (Bergeron and Manjunath, 2006), dilution of protective factors from the epididymal medium and long-term exposure to glycerol). Indeed, the collection and extension of epididymal samples might not be advantageous for long-term storage (Fernández-Santos et al., 2009a).
Moreover, the epididymal environment is hyperosmotic comparing to seminal plasma ( $365 \pm 6 \mathrm{mOsm} / \mathrm{kg}$ according to Tamayo-Canul et al., 2011). Extender osmolality could influence not only the survival of spermatozoa during the refrigerated storage, but also their resistance to cryopreservation. Studies with red deer (Martinez-Pastor et al., 2006b; Fernández-Santos et al., 2007) showed that epididymal spermatozoa seemed to be better cryopreserved in iso or hyperosmotic extenders ( $360-430 \mathrm{mOsm} / \mathrm{kg})$.

Therefore, we have tested the effect of three freezing extenders of different osmolalities $(320,370$ and $420 \mathrm{mOsm} / \mathrm{kg}$ ) and three storage methods (epididymis, collected-undiluted and collected-extended) on the loss of quality of ram epididymal spermatozoa throughout post-mortem time. We aimed at obtaining several storage $\times$ extender combinations that could improve postthawing sperm quality after post-mortem storage of ram epididymal spermatozoa.

\section{Materials and methods}

\subsection{Reagents}

All the products were obtained from Sigma-Aldrich Química SA (Madrid, Spain), except fluorescence probes SYBR-14 (LIVE/DEAD Sperm Viability Kit) and YO-PRO-1, which were acquired from Invitrogen SA (Barcelona, Spain).

\subsection{Animals and experimental design}

Testes were collected from nine adult rams (Churra breed) just after slaughter, and transported at room temperature $\left(22^{\circ} \mathrm{C}\right)$ to the University of León. Samples were collected from September to November. All procedures were performed in accordance with Spanish Animal Protection Regulation RD1201/2005, which conforms to European Union Regulation 2003/65. Protocols were approved by the ethical committee of the University of León (Spain).

The experimental design is summarized in Fig. 1. The first sperm collection ( $0 \mathrm{~h}$ of experimental time) was carried out within the first $2 \mathrm{~h}$ after slaughter. Caudae epididymides were dissected, isolating two symmetrical parts by using a clamp. A sample of epididymal spermatozoa was obtained by performing cuts on one of the parts of the cauda by means of a scalpel.

The sperm mass obtained at $0 \mathrm{~h}$ was split among four aliquots in 10-mL glass tubes. One of them was left undiluted, while the other three were diluted with the same volume of three TTF media (TES-Tris-fructose). These extenders were prepared following instructions for extender M3 in a previous study (Anel et al., 2003). The M3 extender was prepared mixing TES $320 \mathrm{mOsm} / \mathrm{kg}$ and Tris $320 \mathrm{mOsm} / \mathrm{kg}$, adjusting the $\mathrm{pH}$ at 7.2 . Then, a fructose solution at $320 \mathrm{mOsm} / \mathrm{kg}$ was added up to $4 \%$ of the final volume. In this study, the M3 extender was modified to contain 20\% egg yolk and $8 \%$ glycerol (more appropriate for epididymal spermatozoa, unpublished data). Moreover, the osmolality of the three TTF media was modified to 320,370 or $420 \mathrm{mOsm} / \mathrm{kg}_{\bar{\Lambda}}$ varying fructose before adding egg yolk and glycerol. The extenders were 


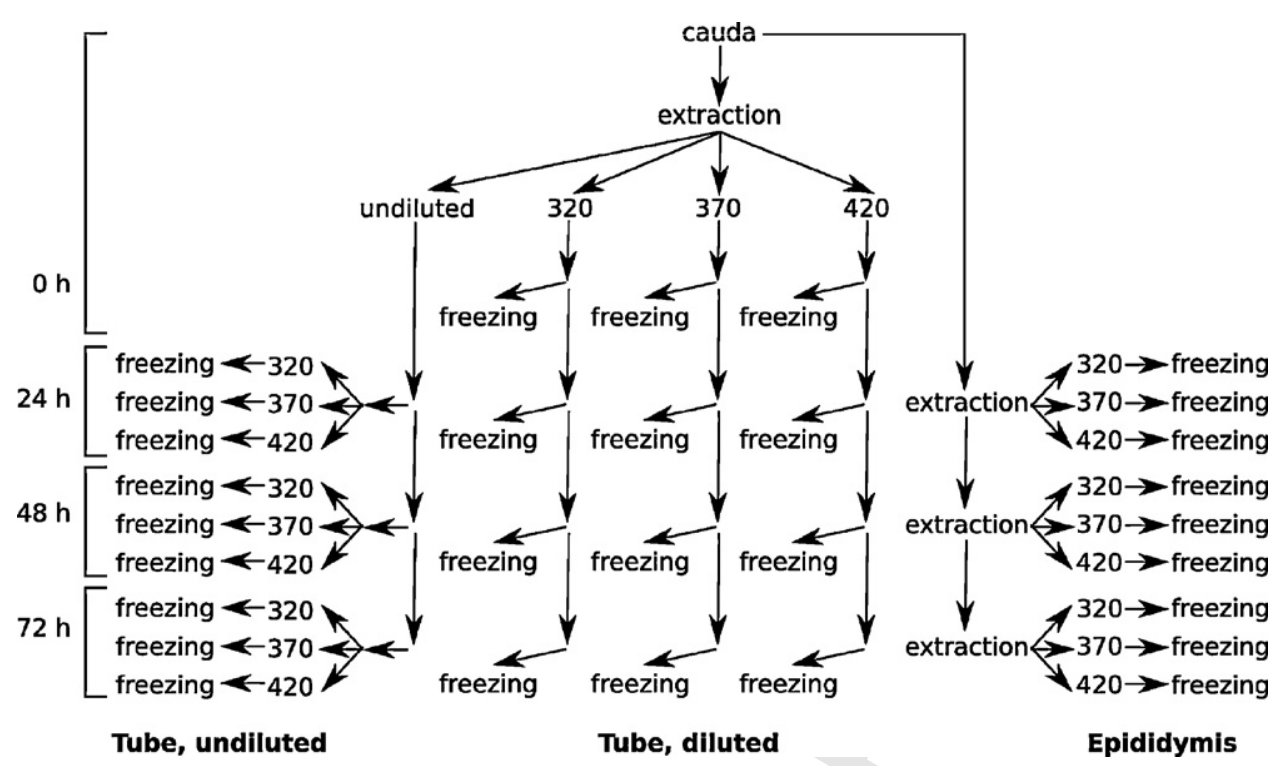

Fig. 1. Experimental design. Samples were stored at $5{ }^{\circ} \mathrm{C}$ within the cauda epididymis, undiluted or extended in three extenders with different osmolalities (320, 370 and $420 \mathrm{mOsm} / \mathrm{kg}$, adjusted before adding egg yolk and glycerol). At each time point ( $0,24,48$ and $72 \mathrm{~h})$, spermatozoa were cryopreserved using each of the three extenders. Samples were assessed before and after cryopreservation.

clarified by centrifugation (removal of coarse particles from egg yolk). Osmolality was tested using a freezing point osmometer (Osmomat 030, Gonotec, Berlin, Germany). According to a previous study (Tamayo-Canul et al., 2011), $370 \mathrm{mOsm} / \mathrm{kg}$ was considered approximately isoosmotic to the epididymal fluid (samples obtained within the first 2-4h post-mortem).

The epididymides, the tube with the undiluted sperm mass and the three tubes with diluted spermatozoa ( 320 , 370 and 420 ) were cooled down to $5^{\circ} \mathrm{C}$, and remained at that temperature for the rest of the experiment. An aliquot of the diluted samples was cryopreserved after this cooling step ( 0 h cryopreservation).

Sperm mass was obtained again at 24,48 and $72 \mathrm{~h}$, from the untouched half of the caudae. The caudae were handled with care in each extraction, performing small cuts in different locations and trying not to disrupt the external capsule. We took great care to obtain samples as homogeneous as possible between sampling times, and to avoid blood contamination. Between sampling times, the epididymides were wrapped with gauze moistened with saline and put inside a plastic bag, which was stored in a refrigerator at $5^{\circ} \mathrm{C}$.

In each sampling time (Fig. 1), the sperm mass just extracted and an aliquot of the undiluted-stored sperm mass were split, extended with each of the extenders ( 320 , 380,420 ) and frozen (see Section 2.4 below). Each of the diluted-stored samples were also extended and frozen.

Sperm quality (CASA and flow cytometry) was assessed after the equilibration time (pre-freezing) and $10 \mathrm{~min}$ after thawing (post-thawing).

\subsection{Sperm cryopreservation and thawing}

At each sampling time, we took three aliquots from the sperm mass extracted at that time and other three from the undiluted-stored sperm mass. Each of these aliquots was extended with each of the three extenders $(320,380,420)$ at $8 \%$ glycerol to achieve a concentration of $200 \times 10^{6} \mathrm{~mL}^{-1}$. For the diluted-stored samples, we took an aliquot from each tube and extended them with the same extender, to achieve the same final concentration.

Samples were packed into $0.25-\mathrm{mL}$ plastic straws and equilibrated for $1 \mathrm{~h}$ at $5^{\circ} \mathrm{C}$. After the equilibration, the straws were frozen using a programmable biofreezer (Kryo 10 Series III; Planer plc., Sunbury-On-Thames, UK) at ${ }^{\wedge}-20^{\circ} \mathrm{C} / \mathrm{min}$ down to $-100^{\circ} \mathrm{C}$. The straws were kept in liquid nitrogen containers for at least one month. Thawing was carried out in a water bath at $65^{\circ} \mathrm{C}$ for $6 \mathrm{~s}$.

\subsection{Motility evaluation}

Motility assessment was carried out using a computerassisted sperm analysis system (ISAS; V.1.2) (Integrated Semen Analysis System; Proiser, Valencia, Spain). Samples were diluted $\left(10-20 \times 10^{6}\right.$ cells $\left./ \mathrm{mL}\right)$ in the same TTF medium that was used for freezing $(320,370$ or 420$)$, and warmed on a $37^{\circ} \mathrm{C}$ plate for $5 \mathrm{~min}$. Then, a $5-\mu \mathrm{L}$ drop was placed into a Makler counting cell chamber ( $10 \mu \mathrm{m}$ depth; Sefi Medical Instruments, Haifa, Israel). The sample was examined at $\times 10$ (negative phase contrast) in a microscope with a warmed stage $\left(38^{\circ} \mathrm{C}\right)$. The standard parameter settings were set at 25 frames/s, $20-90 \mu \mathrm{m}^{2}$ for head area and VCL $>10 \mu \mathrm{m} / \mathrm{s}$ to classify a spermatozoon as motile. At least five sequences or 200 spermatozoa were saved and analyzed afterwards. Reported parameters were curvilinear velocity (VCL, $\mu \mathrm{m} / \mathrm{s}$ ), linearity (LIN, \%), and amplitude of lateral head displacement $(\mathrm{ALH}, \mu \mathrm{m})$. Total motility (TM) was defined as the percentage of spermatozoa with $\mathrm{VCL}>10 \mu \mathrm{m} / \mathrm{s}$, and progressive motility (PM) was defined as the percentage of spermatozoa with $\mathrm{VCL}>25 \mu \mathrm{m} / \mathrm{s}$ and STR $>80 \%$ (straightness, also provided by the system). 


\subsection{Sperm viability and acrosome status}

Viability and acrosomal status were assessed simultaneously using florescence probes and flow cytometry, according to methods described by Martinez-Pastor et al. (2009). Briefly, samples were diluted in PBS at $5 \times 10^{6}$ spermatozoa $/ \mathrm{mL}$, and incubated for $15 \mathrm{~min}$ with $24 \mu \mathrm{M}$ of propidium iodide (PI) and $1 \mu \mathrm{g} / \mathrm{mL}$ of PNAFITC (peanut agglutinin). PI stains red membrane-damaged spermatozoa, whereas PNA-FITC stains the acrosome green if it is damaged or reacted. Thus, we obtained four different subpopulations: red (non-viable sperm, intact acrosome), green (viable sperm, damaged acrosome) red and green (non-viable sperm, damaged acrosome) or non-stained (viable sperm, intact acrosome). The proportion of viable spermatozoa (VIAB) and acrosome-intact spermatozoa (ACR) were used in this study.

Evaluation of flow cytometer parameters was carried out using a FACScalibur flow cytometer (Becton Dicknson System, San Jose, CA, USA) equipped with standard optics and an argon-ion laser, tuned at $488 \mathrm{~nm}$, and running at $200 \mathrm{mV}$. Calibration was carried out periodically using standard beads (Calibrites: Becton Dickson). Data corresponding to the red (FL-3 photodetector) and green (FL-1 photodetector) fluorescence of 10,000 spermatozoa were recorded.

\subsection{Statistical analysis}

Unless otherwise stated, data are presented as mean \pm SEM and significant values are $P<0.05$. Statistical analyses were carried out using the $\mathrm{R}$ statistical environment ( $R$ Development Core Team, 2010). To simplify analysis and interpretation, we assumed that sperm quality was negatively and linearly affected by time, helping to testing if treatments affected the effect of storage time. This assumption was found acceptable for the models tested (using the Akaike Information Criterion ${ }_{\Lambda}$ AIC - to compare with alternative models). Therefore, conservation type and extender osmolality were studied in function on their effects on the intercept or slope of this model both before and after cryopreservation. The analysis was performed using linear mixed-effects model (nlme package), with time (treated as a covariate), storage method and extender (and their interactions) in the fixed part of the model. Analyses were carried out with the pre-freezing data and with the post-thawing data, starting with the general model:

$$
\begin{aligned}
& y_{i j}=\beta_{0 i}+\beta_{1} \cdot \text { time }_{[i]}+\beta_{2} \cdot \operatorname{ext}+\beta_{3} \\
& \text { time } \cdot \operatorname{ext}_{[i]}+\beta_{4} \cdot \text { time } \cdot \operatorname{stor}_{[i]}+\beta_{5} \cdot \text { ext } \cdot \text { stor }+\beta_{6} \\
& \text { time } \cdot \operatorname{ext} \cdot \operatorname{stor}_{[i]}+\beta_{7} \cdot \text { male }_{i}+\varepsilon_{i j}
\end{aligned}
$$

where $y_{i j}$ is the observation $j$ in male $i$, and each $\beta$ is a vector of coefficients for each covariate, factor or interaction. In this model, both the intercept and the slope of time varied for each male (indicated by the subscript [i] in the terms where time participate), forming the random part of the model. We carried out a model comparison according to the AIC, determining that models following this assumption were more informative that models following the assumption that intercept but no slope varied for each male.

An additional analysis was carried out in post-thawing data including the pre-freezing data as a covariate, in order to identify the influence of the pre-freezing quality on the post-thawing quality. Therefore, helping to assess the effect of time, storage and extender on the freezability of the sample.

\section{Results}

The models obtained for each analysis are summarized in Tables 1 and 2. In each table, the basic information of the ANOVA table for each model ( $F$ value, degrees of freedom and resulting $P$ value) is shown, with blanks indicating the factors or interactions removed from the models. We obtained complex models for most variables, with many interactions. In order to facilitate the interpretation of the models, Figs. 2-5 show the distribution of the real data in the form of box-plots for each time, storage method and extender. For each combination of factors, we overplotted the partial linear models for each storage method and each extender. It is possible to compare the slopes and intercepts of each line (indicating the change of the variable through time) among extenders (different lines within plots) and among storage methods (same lines between plots).

As Figs. 2-5 show, sperm quality at pre-freezing and post-thawing decreased with storage time, while the effect of treatment was small. Nonetheless, some treatments stood out because of their higher or lower capacity to maintain sperm quality throughout storage time (described later). Considering the different sampling times, most differences were only noticeable at 48 or 72 h of storage. At $0 \mathrm{~h}$, when the osmolality of the freezing extender was the only experimental factor, only acrosomal status was affected both at pre-freezing (320: $95.2 \pm 13 \%$; 370 : $94.2 \pm 0.8 \%$; 420: $96.4 \pm 0.4 \% ; P=0.027)$ and at post-thawing (320: $82.3 \pm 3.7 \%$; 370: $79.4 \pm 3.5 \% ; 420: 80.1 \pm 3.6 \% ; P=0.025)$. However these differences were small (see boxplots at $0 \mathrm{~h}$ in Figs. 3 and 5).

The pre-freezing assessment allowed us to analyze the effect of the storage method and the extender after extending spermatozoa to the final dilution, but without considering cryopreservation. Time had a significant effect on all quality variables (Table 1), as expected in post-mortem storage. The analysis of the different models showed that the quality variables were also influenced by the storage treatments (storage method and extender), although in some cases (TM, VCL), the extender did not have any significant effect. The table shows that storage affected the slope of the model in most cases (interaction with time; expect for LIN), while the effect of the storage method was modulated by the extender (VIAB and ACR) and for TM and ACR a triple interaction was found. These interactions are better visualized in Figs. 2 and 3. Motility variables (Fig. 2) clearly decreased with storage time in all cases, although it was less evident for VCL. Total motility underwent a sharper decrease in the samples stored diluted $(P<0.01)$ comparing to the other two methods, except when diluted-stored in 320 (at $72 \mathrm{~h}$, 320: $47.5 \pm 3.4 \%$ vs. $370: 16.3 \pm 2.3 \%$ and $420: 23.5 \pm 3.5 \%$; 

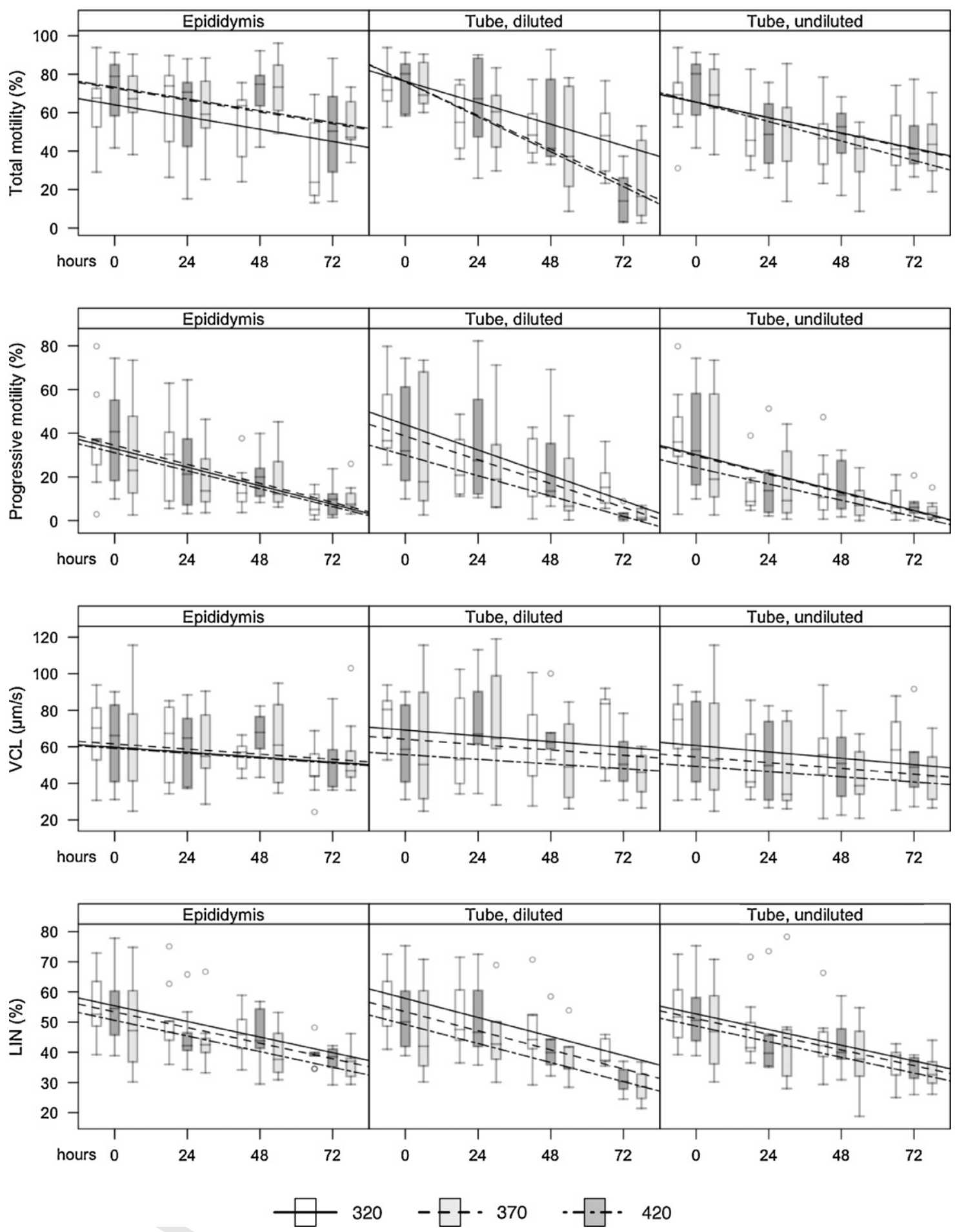

Fig. 2. Motility data yielded by CASA in the pre-freezing assessment. Background box-plots show the distribution of data for each treatment (storage method $\times$ extender) and time combination. Boxes span from the 1 st to the 3rd quartile, with the inner line showing the median. Whiskers span to 1.5 times the interquartile range, with observations beyond displayed as hollow dots. Lines show the linear estimation of the post-mortem time effect on sperm quality, for each extender within each conservation method (predicted after fitting the actual data). Time significantly decreased motility parameters, except VCL (Table 1). Motility was better preserved by the 320 extender when samples were diluted-stored, but this extender yielded the lowest motility for the samples stored in the epididymis. Extender 370 performed worse in general, except when samples were stored undiluted in a tube. In general, extending the samples with 320 yielded higher LIN than extending with 420 . 
Table 1

Summary of the models selected for analyzing of the response variables within the pre-freezing data. The table shows the $F$ value, degrees of freedom and $P$ values for each explanatory variable and their interactions, obtained from the ANOVA table of the linear model. Empty cells indicate that the explanatory elements were non-significant and they were removed from the model during its optimization.

\begin{tabular}{|c|c|c|c|c|c|c|}
\hline \multirow[t]{2}{*}{$\lambda^{\text {Response variable }}$} & \multirow[t]{2}{*}{ Intercept } & \multicolumn{5}{|c|}{$\underline{\text { Explanatory variables }}$} \\
\hline & & $\Lambda^{\text {Time }}$ & Extender & Time $\times$ storage & Extender $\times$ storage & Time $\times$ extender $\times$ storage \\
\hline TM & $\begin{array}{l}F_{1,255}=527.3 \\
(P<0.001)\end{array}$ & $\begin{array}{l}F_{1,255}=9.2 \\
(P=0.003)\end{array}$ & & $\begin{array}{l}F_{2,255}=11.2 \\
(P<0.001)\end{array}$ & & $\mathrm{F}_{6,255}=3.5(P=0.003)$ \\
\hline PM & $\begin{array}{l}F_{1,259}=72.7 \\
(P<0.001)\end{array}$ & $\begin{array}{l}F_{1,259}=21.9 \\
(P<0.001)\end{array}$ & $\begin{array}{l}F_{2,259}=6.9 \\
(P=0.001)\end{array}$ & $\begin{array}{l}F_{2,259}=4.7 \\
(P=0.010)\end{array}$ & & \\
\hline VCL & $\begin{array}{l}F_{1,259}=17,651.7 \\
(P<0.0 \hat{0} 1)\end{array}$ & $\begin{array}{l}F_{2,259}=3.7 \\
(P=0.027)\end{array}$ & & $\begin{array}{l}F_{3,259}=3.7 \\
(P=0.012)\end{array}$ & & \\
\hline LIN & $\begin{array}{l}F_{1,261}=1015.7 \\
(P<0.001)\end{array}$ & $\begin{array}{l}F_{1,261}=19.0 \\
(P<0.001)\end{array}$ & $\begin{array}{l}F_{2,261}=19.0 \\
(P<0.001)\end{array}$ & & & \\
\hline VIAB & $\begin{array}{l}F_{1,255}=1100.2 \\
(P<0.001)\end{array}$ & $\begin{array}{l}F_{1,255}=178.2 \\
(P<0.001)\end{array}$ & $\begin{array}{l}F_{2,255}=10.2 \\
(P<0.001)\end{array}$ & $\begin{array}{l}F_{2,255}=18.4 \\
(P<0.001)\end{array}$ & $\begin{array}{l}F_{4,255}=2.4 \\
(P=0.050)\end{array}$ & \\
\hline ACR & $\begin{array}{l}F_{1,249}=5043.1 \\
(P<0.001)\end{array}$ & $\begin{array}{l}F_{1,249}=277.6 \\
(P<0.001)\end{array}$ & $\begin{array}{l}F_{2,249}=10.6 \\
(P<0.001)\end{array}$ & $\begin{array}{l}F_{2,249}=10.7 \\
(P<0.001)\end{array}$ & $\begin{array}{l}F_{4,249}=3.3 \\
(P=0.011)\end{array}$ & $F_{6,249}=2.3(P<0.035)$ \\
\hline
\end{tabular}

TM: total motility (\%); PM: progressive motility (\%); VCL: c్र urvilinear velocity ( $\mu \mathrm{m} / \mathrm{s}) ;$ LIN: $\lambda_{\Lambda}$ inearity index (\%), VIAB: viability spermatozoa (\%), ACR: jntact acrosomes (\%).

$P<0.01)$. Total motility was maintained in the samples diluted-stored with 320 similarly to the samples stored in the epididymis or undiluted. However, when samples were stored in the epididymis, 320 was suboptimal comparing with 370 and $420(P<0.05$; at $72 \mathrm{~h}, 320: 35.8+2.6 \%$ vs. $370: 48.8 \pm 2.0 \%$ and $420: 53.9 \pm 1.6 \%)$. There were small differences among storage methods or extenders for the kinematic parameters. VCL was slightly higher in dilutedstored samples extended with 320 (although differences were only evident at $72 \mathrm{~h} ; 72.4 \pm 3.6 \mu \mathrm{m} / \mathrm{s}$ vs. overall for others $51.0 \pm 0.3 \mu \mathrm{m} / \mathrm{s}, P<0.05$ ). LIN decreased with time, being influenced by the extender type (Table 1 ). In this case, 320 exerted an overall positive effect on LIN, while samples extended with 420 yielded lower LIN.

Flow cytometry parameters of pre-freeze samples are visualized in Fig. 3. Sperm viability was influenced both by extender and storage choice. Viability dropped more sharply when samples were stored diluted $(P<0.05)$, resulting in significantly lower viability at $72 \mathrm{~h}$ for 370 and 420 , whereas samples diluted-stored with 320 were not significantly different to other storage methods (320:
$29.9 \pm 1.6 \%$ vs. $370: 18.1 \pm 1.1 \%$ and $420: 22.1 \pm 1.2 \%$; overall: $31.7 \pm 0.2 \%)$. Epididymis and undiluted storage behaved similarly, and extending with 420 kept viability significantly higher than the other extenders in both methods (at $72 \mathrm{~h}$, epididymis: $39.1 \pm 0.8 \%$ and undiluted: $43.1 \pm 1.8 \%$; other extenders: $31.6 \pm 0.3 \%$ ). In the case of acrosomal status, the presence of multiple interactions made the interpretation of the results difficult (Table 1). Thus, when we analyzed samples stored in the epididymis, we found that, despite the overall significance of extender type, when samples were stored undiluted we could not find any difference among the three extenders. When samples were diluted-stored, extending with 370 increased acrosomal damage $(P<0.05$ after $24 \mathrm{~h}$; at $72 \mathrm{~h}, 68.8+2.0 \%$ vs. $85.7 \pm 0.1 \%$, overall for other combinations). Conversely 420 tended to decrease the negative effect of time on acrosomal status $(P=0.052)$. In general, acrosomal status was slightly improved by storing the samples in the epididymis, especially at $48 \mathrm{~h}(83.7 \pm 0.2 \%$ vs. $77.5 \pm 0.2 \%$, comparing with the other methods, $P<0.05$ ), but differences faded at $72 \mathrm{~h}$, excluding samples diluted-stored in 370 .

Table 2

Summary of the models selected for analyzing of the response variables within the post-thawing data. The table shows the $F$ value, degrees of freedom and $P$ values for each explanatory variable and their interactions, obtained from the ANOVA table of the linear model. Empty cells indicate that the explanatory elements were non-significant and they were removed from the model during its optimization.

\begin{tabular}{|c|c|c|c|c|c|c|c|}
\hline \multirow[t]{2}{*}{$\AA^{\text {Response variables }}$} & \multirow[t]{2}{*}{ Intercept } & \multicolumn{6}{|c|}{ Explanatory variables } \\
\hline & & $\lambda^{\text {Time }}$ & Extender & Time $\times$ storage & $\begin{array}{l}\text { Time } \times \\
\text { extender }\end{array}$ & $\begin{array}{l}\text { Extender } \times \\
\text { storage }\end{array}$ & $\begin{array}{l}\text { Time } \times \text { extender } \times \\
\text { storage }\end{array}$ \\
\hline TM & $\begin{array}{l}F_{1,255}=741.7 \\
(P<0.001)\end{array}$ & $\begin{array}{l}F_{1,255}=22.4 \\
(P<0.001)\end{array}$ & & $\begin{array}{l}F_{2,255}=6.9 \\
(P=0.001)\end{array}$ & & $\begin{array}{l}F_{6,255}=2.1 \\
(P=0.052)\end{array}$ & \\
\hline PM & $\begin{array}{l}F_{1,255}=864.1 \\
(P<0.001)\end{array}$ & $\begin{array}{l}F_{1,255}=47.0 \\
(P<0.001)\end{array}$ & $\begin{array}{l}F_{2,255}=2.6 \\
(P=0.078)\end{array}$ & $\begin{array}{l}F_{2,255}=4.1 \\
(P=0.018)\end{array}$ & & $\begin{array}{l}F_{4,255}=3.6 \\
(P=0.072)\end{array}$ & \\
\hline VCL & $\begin{array}{l}F_{1,261}=895.7 \\
(P<0.001)\end{array}$ & $\begin{array}{l}F_{1,261}=9.2 \\
(P=0.003)\end{array}$ & & $\begin{array}{l}F_{2,256}=10.1 \\
(P<0.001)\end{array}$ & & & \\
\hline LIN & $\begin{array}{l}F_{1,261}=2194.2 \\
(P<0.001)\end{array}$ & $\begin{array}{l}F_{1,261}=42.9 \\
(P<0.001)\end{array}$ & $\begin{array}{l}F_{2,261}=10.0 \\
(P<0.001)\end{array}$ & & & & \\
\hline VIAB & $\begin{array}{l}F_{1,252}=2333.2 \\
(P<0.001)\end{array}$ & & $\begin{array}{l}F_{2,2572}=5.1 \\
(P=0.006)\end{array}$ & $\begin{array}{l}F_{3,252}=4.3 \\
(P=0.006)\end{array}$ & $\begin{array}{l}F_{3,252}=2.6 \\
(P=0.037)\end{array}$ & & $\begin{array}{l}F_{3,252}=2.1 \\
(P<0.051)\end{array}$ \\
\hline ACR & $\begin{array}{l}F_{1,252}=7984.3 \\
(P<0.001)\end{array}$ & & $\begin{array}{l}F_{2,252}=21.9 \\
(P=0.001)\end{array}$ & $\begin{array}{l}F_{2,252}=9.6 \\
(P<0.001)\end{array}$ & $\begin{array}{l}F_{2,252}=3.3 \\
(P<0.020)\end{array}$ & $\begin{array}{l}F_{2,252}=3.3 \\
(P<0.011)\end{array}$ & $\begin{array}{l}F_{2,252}=3.8 \\
(P<0.044)\end{array}$ \\
\hline
\end{tabular}

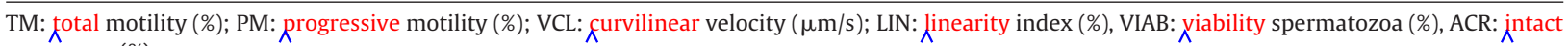
acrosomes (\%). 

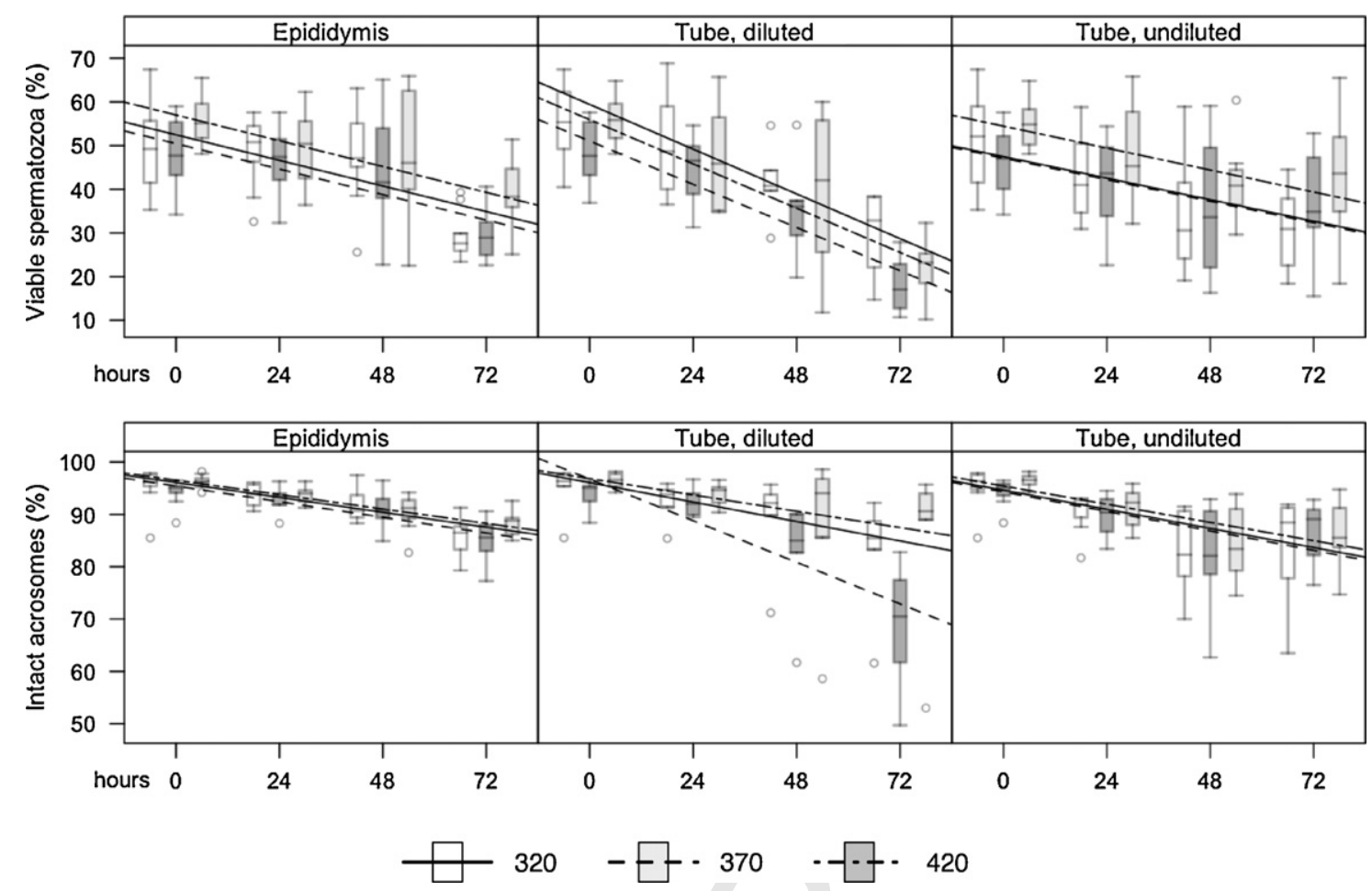

Fig. 3. Viability and acrosomal status yielded by flow cytometry in the pre-freezing assessment. The description of the plots is given in the legend of Fig. 2 . Post-mortem time decreased viability in all cases, but the slope was significantly steeper when samples were stored diluted with 370 or 420 . Extender 420 yielded a slightly higher viability when combined with the storage in the epididymis or undiluted in a tube, whereas extender 370 yielded lower viability if the samples were diluted-stored. Acrosomal status showed no differences among extenders when spermatozoa were stored in the epididymis or undiluted, but it dropped faster if samples were stored diluted in 370 . In general, storing the spermatozoa in the epididymis and diluting with 320 or 420 better maintained acrosomal status at pre-freezing.

Post-thawing assessment showed significant changes on sperm quality comparing to pre-freezing values. A comparison controlling for treatments indicated a decrease of progressive motility, viability and acrosomal status (mean difference and SEM: $-1.6 \pm 0.4,-4.2 \pm 0.4$ and $-4.2 \pm 0.2$, respectively; $P<0.001$ ) and an increase of VCL and ALH (mean difference and SEM: $-2.2 \pm 0.5$ and $0.06 \pm 0.02$, respectively; $P<0.001$ ). Nevertheless, both extender and storage choice modulated this decrease with storage time (Table 2). The trends of motility variables with time (Fig. 4) were similar to those of pre-freezing analyses, but we could detect some critical differences. Total motility was better preserved when the samples remained in the epididymis and 420 was used for freezing $(P<0.05$ at $72 \mathrm{~h}$, 420: $53.9 \pm 1.6 \%$ vs. $320: 35.8 \pm 2.6 \%$ and $370: 48.8 \pm 3 \%$, overall: $4 \hat{1} \pm 0.3 \%$ ). Interestingly, diluted-stored samples achieved similar total motility when using 320 , but not with the other extenders (at $72 \mathrm{~h}, 47.5+3.4 \%$ vs. 370 : $16.3 \pm 2.3 \%$ and 420 : $23.5 \pm 3.5 \%$ ). Similarly to the prefreezing results, storage time caused the decrease of both progressive motility ( $0 \mathrm{~h}: 25.0 \pm 0.2 \% ; 72 \mathrm{~h}: 9.0 \pm 0.1 \%)$ and linearity ( $0 \mathrm{~h}: 51.3 \pm 0.1 \%$; $7 \hat{2} \mathrm{~h}: 38 \pm 0.1 \%)$. Progressive motility was improved by diluted storage and, within this storage method, by using $320(P<0.05)$, most noticeably at $72 \mathrm{~h}(18.7 \pm 1.6 \%$ vs. $370: 5.9 \pm 0.8 \%$ and 420 : $6.2 \pm 0.8 \% ; \quad P<0.01)$. Contrasting with the pre-freezing assessment, VCL $(\mu \mathrm{m} / \mathrm{s})$ showed a decrease with storage time ( $0 \mathrm{~h}: 69.5 \pm 0.3 ; 72 \mathrm{~h}$ : $55.5 \pm 0.1$ ), which was significantly ameliorated in the combinations epididymis $\times 420(72 \mathrm{~h}: 59.8 \pm 0.8)$ and diluted $\times 320(72 \mathrm{~h}$ : $64.6 \pm 1.5)$.

Post-thawing viability and acrosomal status (Fig. 5) only underwent small variations with storage time $(0 \mathrm{~h}$ : $32.2 \pm 0.1 \%, 82.7 \pm 0.1 \% ; \quad 72 \mathrm{~h}: 30.5 \pm 0.1 \%, \quad 77.2 \pm 0.1 \%$; overall values for viability and acrosomal status, respectively). The combination diluted $\times 370$ was again the less suitable for both variables (at $72 \mathrm{~h}$, viability: $15.1+1.1 \%$ and acrosomal status: $54.4 \pm 1.1 \%$ ). Post-thawing viability did not change significantly with post-mortem time when spermatozoa were stored in the epididymis or undiluted ( $0 \mathrm{~h}$, epididymis: $31.3 \pm 0.4 \%$ and undiluted: $33.1 \pm 0.4 \%$ vs. 72 h, epididymis: $29.4+0.2 \%$ and undiluted: $36.7+0.4 \%$ ), but it decreased if stored diluted ( $0 \mathrm{~h}: 32.2 \pm 0.5 \%$ vs. $72 \mathrm{~h}: 23.9 \pm 0.6 \%)$. Moreover, viability was improved by the epididymis $\times 420$ combination $(P<0.01$ at $72 \mathrm{~h}, 420$ : $33.0 \pm 0.6 \%$ vs. $320: 26.9 \pm 0.6 \%$ and $370: 28.4 \pm 0.8 \%$ ), and by the diluted $\times 320$ combination $(P<0.01$ at $72 \mathrm{~h}, 320$ : $32.9+1.7 \%$ vs. $370: 15.1 \pm 1.1 \%$ and $420: 23.9 \pm 1.7 \%$ ). In fact, the viability of the diluted $\times 320$ combination was not significantly different in this combination than in the epididymis $\times 420$. The proportion of spermatozoa with intact acrosomes did not change significantly with time when samples were stored in the epididymis or when 320 or 420 were used (within any storage method; 0 h: $82.8 \pm 0.1 \%$ vs. $72 \mathrm{~h}: 79.6 \pm 0.1 \%$ ). Acrosomal status decreased with time when samples were stored undiluted 

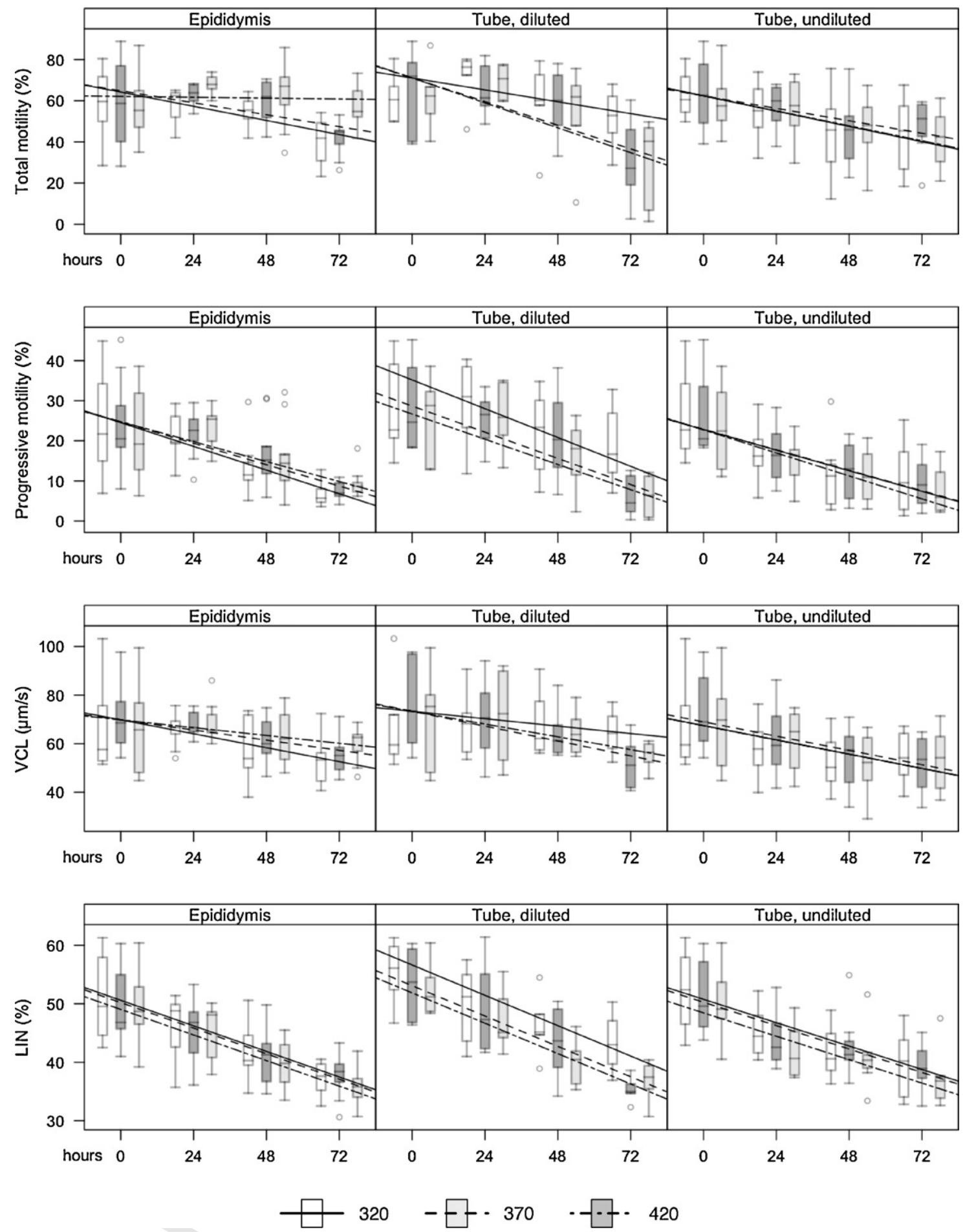

Fig. 4. Motility data yielded by CASA in the post-thawing assessment. The description of the plots is given in the legend of Fig. 2 . Total motility post-thawing was maintained throughout post-mortem time by combining epididymal storage and extension in 420 , although storing the spermatozoa diluted in 320 yielded similar results. The latter combination (diluted-stored with 320) yielded higher results for the rest of the kinematic parameters.

( $P<0.001 ; 0$ h: $84.1 \pm 0.2 \%$ vs. 72 h: $79.0 \pm 0.3 \%)$, although results at $72 \mathrm{~h}$ were not different to other methods except for diluted $\times 370$. In all cases, the use of 370 resulted in a significantly lower post-thawing proportion of intact acrosomes, which was more dramatic when spermatozoa had been diluted-stored in 370 ( $72 \mathrm{~h}$ : epididymis: $77.9 \pm 0.8 \%$, diluted: $54.4 \pm 1.1 \%$, undiluted: $77.5 \pm 1.0 \%$; overall except 370: $80.0 \pm 0.2 \%$ ). 

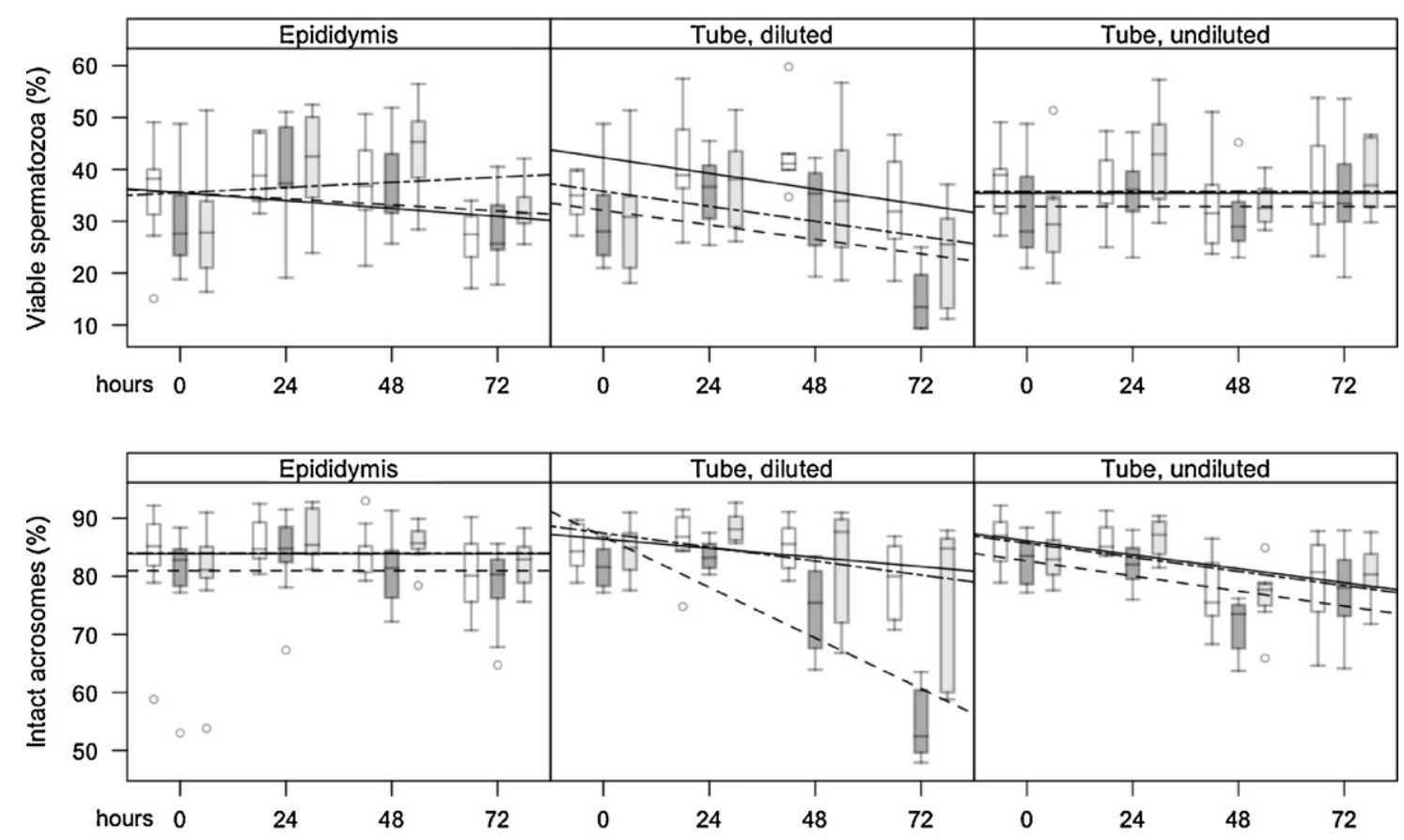

When including the pre-freezing values as a covariate in the post-thawing models, the effect of the extender became non-significant for total motility, whereas the effect of the conservation method (interaction with time) became non-significant for viability and acrosomal status. This indicates that the effects of the extender on total motility and conservation method on viability and acrosomal status were exerted pre-freezing, rather than during the freezingthawing process. Regarding the other factors (Table 2), they remained significant even after including the pre-freezing values as a covariate, suggesting that they might affect not only sperm quality during storage and equilibration, but also the spermatozoa freezability.

\section{Discussion}

Three major conclusions can be extracted from our study, possibly the first one testing storage methods before freezing ram epididymal spermatozoa. First, ram epididymal spermatozoa seem to be resilient cells, which could be stored in different ways while yielding similar quality after cryopreservation. Second, they seem to tolerate well osmotic challenges, and to adapt to media of different osmolality. Third, whenever we detected noticeable differences, they occurred in specific storage $\times$ extender combinations, rather than in a specific storage method or extender.
In previous studies on refrigerated storage of epididymal spermatozoa (Tamayo-Canul et al., 2011), we hinted that extender osmolality (prior to addition of egg yolk or glycerol) could have an impact on the storage of epididymal spermatozoa. Deer epididymal spermatozoa yielded higher motility after being cryopreserved with a 380 or $430 \mathrm{mOsm} / \mathrm{kg}$ extender rather than with a $320 \mathrm{mOsm} / \mathrm{kg}$ extender (Martinez-Pastor et al., 2006b), and similar results were obtained by Fernández-Santos et all. (2007). The osmolality of the epididymal lumen increases from the caput to the cauda epididymis (Cooper and Yeung, 2003), being clearly hyperosmotic in the cauda (deer: $375 \pm 8 \mathrm{mOsm} / \mathrm{kg}$ (Martinez-Pastor et al., 2005b); ram: $365 \pm 6 \mathrm{mOsm} / \mathrm{kg}$ at $2 \mathrm{~h}$ and $375 \pm 8$ (Tamayo-Canul et al., 2011); mean \pm SEM by 24 h post-mortem). Thus, hyperosmotic extenders could favour sperm cryopreservation, not only because of being isoosmotic to epididymal fluids, but also because they could increase dehydration prior to freezing (Liu and Foote, 1998). Nevertheless, our results did not show any dramatic differences among extenders at $0 \mathrm{~h}$. This suggests that ram epididymal spermatozoa may tolerate a high range of osmolalities undergoing only small changes in pre or post-thawing quality.

Considering storage methods, each of the options that we tested had advantages and disadvantages, as showed in the introduction. Despite these differences, we found a lack of large differences among them. It is possible that the 
positive and negative effects of each method could compensate themselves, resulting in similar sperm quality preand post-freezing. Another explanation, compatible with the previous hypothesis, is that the epididymal samples would be resilient enough to withstand the detrimental effects of post-mortem storage, irrespectively of the storage method. In fact, Fernández-Santos et al. (2009a) tested several storage options for red deer epididymal spermatozoa (epididymis, extended and extended with vitamin C), but, apart from the motility-stimulating effect of vitamin $C$, differences only appeared at long post-mortem times (96 or $192 \mathrm{~h}$ ). Larger post-mortem times could have disclosed larger the differences among our treatments, but, for the purposes of the present study, it was impractical.

Notwithstanding the lack of large differences among extenders or storage methods, it was clear that several of their combinations either improved or deteriorated spermatozoa quality (pre and post-thawing) throughout storage time. Thus, 420 improved sperm quality when used to freeze samples stored in the epididymis, while 320 was the most appropriate one for the diluted-stored samples. These two combinations could be considered as the most adequate in the present study, especially at long postmortem times. Conversely, the diluted-stored method was clearly detrimental whenever 370 or 420 was used to store the samples.

It is difficult to explain the improved performance of the $420 \times$ epididymal storage and $320 \times$ diluted storage combinations. In order to propose an explanation for the first combination, we have to consider that previous studies have demonstrated that the osmolality of the epididymal medium increases with post-mortem time (Martinez-Pastor et al., 2005b; Tamayo-Canul et al., 2011). Thus, epididymal spermatozoa might develop a continuous adaptation while being submitted to an increasingly hypertonic environment. It has been proposed that epididymal spermatozoa undergo intracellular accumulation of osmolytes, which would be useful for facing osmotic challenges upon ejaculation (Cooper and Yeung, 2003; Yeung et al., 2006). We hypothesise that longer postmortem times, being concomitant to higher osmolality, would induce these mechanisms. Indeed, extending these spermatozoa in hypoosmotic media (here, 320 extenders) might induce a transient excess of intracellular water, which would render spermatozoa more vulnerable to cryopreservation. Moreover, prolonged storage in the cauda epididymis could cause physiological changes of uncertain consequences (Rodriguez and Bustos Obregon, 1996; Martinez-Pastor et al., 2005a). Further studies should test this hypothesis, analyzing the changes in sperm osmolytes and cell volume.

The situation of diluted-stored samples was rather the opposite. In this case, the hypoosmotic extender (320) yielded the highest quality. A possible explanation is that, once collected and diluted, epididymal spermatozoa would undergo an adaptation to the new environment, which would be improved by the hypotonicity of the medium. Spermatozoa in the cauda epididymis must contact the hypotonic seminal plasma during ejaculation, and then the much hypotonic (relative to the epididymal medium) female genital tract (Yeung et al., 2006). Epididymal spermatozoa collected shortly after post-mortem might be better prepared to hypoosmotic challenges and to the adaptation to a lower osmolality (Cooper and Yeung, 2003; Yeung et al., 2006; Sahin et al., 2009), which might explain the good pre and post-freezing results of samples extended in 320 shortly after the death of the male and stored.

Two questions remain unanswered: why extender choice seems not to be important when the sperm mass is stored undiluted, and why 370 have such a detrimental effect on acrosomal status when samples are dilutedstored. For the first question, we must remind the special status of undiluted-stored spermatozoa, remaining in epididymal medium but not submitted to the osmolality and $\mathrm{pH}$ changes of epididymis-stored spermatozoa. Therefore, undiluted-stored spermatozoa might remain highly adaptable to a wide range of osmotic challenges, thus explaining the similarity of results among extenders after thawing. Nevertheless, undiluted-stored samples did not achieve better post-thawing results, as it would be expected. The second question is also difficult to answer. The acrosome is sensitive to osmotic stress and other challenges (Harrison and Fléchon, 1980). However, acrosomal damage remained very low in all cases, including extenders 320 and 420 , which would submit spermatozoa to osmotic stress upon dilution. Therefore, we propose that the 370 extender might cause an osmotic imbalance or modifications in membrane permeability with increasing time, enhancing acrosomal disruption. Further studies are needed.

A caveat must be added. We adjusted the osmolality of the extenders by varying fructose concentration. Spermatozoa can readily use fructose as an energy source, therefore the different fructose concentration might have affected sperm survival beyond its osmotic effects. However, our results suggest that the higher availability of fructose in the 380 and 420 extenders had a minor impact in the study. This makes sense considering that spermatozoa were stored at $5{ }^{\circ} \mathrm{C}$, therefore the metabolic activity would be depressed and fructose may not have been a limiting factor in any extender. Moreover, other methods for varying the osmolality of the extenders would have added more important confounding factors. Increasing the TES/Tris would have modified the buffering capacity of the extenders, possibly impacting the sperm survival at long times. Moreover, using other molecules to increase osmolality would have added confounding factors, making the interpretation of the results more difficult.

In conclusion, this study contributes to the scarce information on the effect of post-mortem time to the post-thawing quality of epididymal spermatozoa. Ram epididymal spermatozoa seemed to endure well the different storage methods and extender osmolalities. However, storing the spermatozoa in the epididymis and then freezing with a hyperosmotic extender $(420 \mathrm{mOsm} / \mathrm{kg})$ or collecting the spermatozoa and maintaining them extended in a hypoosmotic extender $(320 \mathrm{mOsm} / \mathrm{kg}$ ) might improve their overall quality and post-thawing results, especially at long times post-mortem. These findings have practical applications, considering the different situations that may involve the preservation of post-mortem samples. In the typical situation, in which a valuable male dies unexpectedly, the scrotum could be simply refrigerated 
as usual, and these spermatozoa would be frozen using a hyperosmotic extender. However, if samples were to be sent away for freezing and package volume is important, the sperm mass could be extracted and diluted with a hypoosmotic extender, allowing sending the samples in small tubes; if no extender were available, samples could be simply sent undiluted (taking into account the acceptable results of undiluted-stored samples). Moreover, we can advice not using an extender isoosmotic with the epididymal medium ( $370 \mathrm{mOsm} / \mathrm{kg}$ in this study). A caveat must be added, that these recommendations might be only valid for osmolalities around the ones tested in this study ( $420 \mathrm{mOsm} / \mathrm{kg}$ for the hyperosmotic extenders and $320 \mathrm{mOsm} / \mathrm{kg}$ for the hypoosmotic extenders). Extenders with different osmolalities should be appropriately tested.

As described in the introduction, we are currently using epididymal spermatozoa in the production breeds Churra and Assaf, introducing this kind of germplasm source in their genetic improvement programs. The small differences observed in this study could reflect in important changes after applying artificial insemination, which might be critical in the case of spermatozoa from endangered breeds or valuable males.

\section{Acknowledgements}

This work was supported in part by INIA (RZ200700011-00-00, RZ2010-00005-00-00). The authors thank to Elena López, Leticia Ordás, Susana Gomes and Mariǐa Nicolás for their help in the acquisition and analysis of the samples, and to Manuel Ramón (CERSYRA, Spain) for his help with the statistical analysis. Felipe Martínez-Pastor was supported by the Ramón y Cajal program (RYC-200802560, MICINN, Spain).

\section{References}

Anel, L., Alvarez, M., Anel, E., Martinez-Pastor, F., Martinez, F., Chamorro, C., de Paz, P., 2011. Evaluation of three different extenders for use in emergency salvaging of epididymal spermatozoa from a Cantabric brown bear. Reprod. Domest. Anim. 46, 85-90.

Anel, L., Alvarez, M., Martinez-Pastor, F., Garcia-Macias, V., Anel, E., de Paz, P., 2006. Improvement strategies in ovine artificial insemination. Reprod. Domest. Anim. 41 (Suppl. 2), 30-42.

Anel, L., de Paz, P., Alvarez, M., Chamorro, C.A., Boixo, J.C., Manso, A., González, M., Kaabi, M., Anel, E., 2003. Field and in vitro assay of three methods for freezing ram semen. Theriogenology 60, 1293-1308.

Bergeron, A., Manjunath, P., 2006. New insights towards understanding the mechanisms of sperm protection by egg yolk and milk. Mol. Reprod. Dev. 73, 1338-1344.

Comizzoli, P., Mauget, R., Mermillod, P., 2001. Assessment of in vitro fertility of deer spermatozoa by heterologous IVF with zona-free bovine oocytes. Theriogenology 56, 261-274.

Cooper, T.G., Yeung, C.H., 2003. Acquisition of volume regulatory response of sperm upon maturation in the epididymis and the role of the cytoplasmic droplet. Microsc. Res. Tech. 61, 28-38.

Ehling, C., Rath, D., Struckmann, C., Frenzel, A., Schindler, L., Niemann, H., 2006. Utilization of frozen-thawed epididymal ram semen to preserve genetic diversity in Scrapie susceptible sheep breeds. Theriogenology 66, 2160-2164.

Fernández-Santos, M.R., Domínguez-Rebolledo, A.E., Esteso, M.C., Garde, J.J., Martínez-Pastor, F., 2009a. Refrigerated storage of red deer epididymal spermatozoa in the epididymis, diluted and with vitamin C supplementation. Reprod. Domest. Anim. 44, 212-220.
Fernández-Santos, M.R., Martínez-Pastor, F., García-Macías, V., Esteso, M.C., Soler, A.J., de Paz, P., Anel, L., Garde, J.J., 2007. Extender osmolality and sugar supplementation exert a complex effect on the cryopreservation of Iberian red deer (Cervus elaphus hispanicus) epididymal spermatozoa. Theriogenology 67, 738-753.

Fernández-Santos, M.R., Martínez-Pastor, F., Matias, D., DomínguezRebolledo, A.E., Esteso, M.C., Montoro, V., Garde, J.J., 2009b. Effects of long-term chilled storage of red deer epididymides on DNA integrity and motility of thawed spermatozoa. Anim. Reprod. Sci. 111, 93-104.

Harrison, R.A., Fléchon, J.E., 1980. Immunocytochemical detection of acrosomal damage following cold shock: loss of acrosin from the acrosomal region of ram, bull and boar spermatozoa. Reprod. Nutr. Dev. 20, 1801-1810.

Hewitt, D.A., Leahy, R., Sheldon, I.M., England, G.C., 2001. Cryopreservation of epididymal dog sperm. Anim. Reprod. Sci. 67, 101-111.

Jones, R., 2004. Sperm survival versus degradation in the Mammalian epididymis: a hypothesis. Biol. Reprod. 71, 1405-1411.

Kaabi, M., Paz, P., Alvarez, M., Anel, E., Boixo, J.C., Rouissi, H., Herraez, P., Anel, L., 2003. Effect of epididymis handling conditions on the quality of ram spermatozoa recovered post-mortem. Theriogenology 60 , 1249-1259.

Lambrechts, H., van Niekerk, F.E., Coetzer, W.A., Cloete, S.W., van der Horst, G., 1999. The effect of cryopreservation on the survivability, viability and motility of epididymal African buffalo (Syncerus caffer) spermatozoa. Theriogenology 52, 1241-1249.

Liu, Z., Foote, R.H., 1998. Bull sperm motility and membrane integrity in media varying in osmolality. J. Dairy Sci. 81, 1868-1873.

Martinez-Pastor, F., Diaz-Corujo, A.R., Anel, E., Herraez, P., Anel, L., de Paz, P., 2005a. Post mortem time and season alter subpopulation characteristics of Iberian red deer epididymal sperm. Theriogenology 64, 958-974.

Martinez-Pastor, F., Garcia-Macias, V., Alvarez, M., Chamorro, C., Herraez, P., de Paz, P., Anel, L., 2006a. Comparison of two methods for obtaining spermatozoa from the cauda epididymis of Iberian red deer. Theriogenology $65,471-485$.

Martinez-Pastor, F., Guerra, C., Kaabi, M., Diaz, A.R., Anel, E., Herraez, P., de Paz, P., Anel, L., 2005b. Decay of sperm obtained from epididymes of wild ruminants depending on postmortem time. Theriogenology 63, 24-40.

Martinez-Pastor, F., Martínez, F., Alvarez, M., Maroto-Morales, A., GarcíaAlvarez, O., Soler, A.J., Garde, J.J., de Paz, P., Anel, L., 2009. Cryopreservation of Iberian red deer (Cervus elaphus hispanicus) spermatozoa obtained by electroejaculation. Theriogenology 71, 628-638.

Martinez-Pastor, F., Martínez, F., García-Macías, V., Esteso, M.C., Anel, E., Fernández-Santos, M.R., Soler, A.J., de Paz, P., Garde, J., Anel, L., 2006b. A pilot study on post-thawing quality of Iberian red deer spermatozoa (epididymal and electroejaculated) depending on glycerol concentration and extender osmolality. Theriogenology 66, 1165-1172.

Martins, C.F., Driessen, K., Costa, P.M., Carvalho-Neto, J.O., de Sousa, R.V., Rumpf, R., Dode, M.N., 2009. Recovery, cryopreservation and fertilization potential of bovine spermatozoa obtained from epididymides stored at 5 degrees $C$ by different periods of time. Anim. Reprod. Sci. 116, 50-57.

R Development Core Team, 2010. R: A Janguage and Environment for Statistical Computing. R Foundation for Statistical Computing, Vienna, Austria. ISBN 3-900051-07-0, URL: http://www.R-project.org/.

Rodriguez, H., Bustos Obregon, E., 1996. Seasonality and freezability vs routine parameters in stallion semen. Histol. Histopathol. 11, 427-430.

Sahin, E., Petrunkina, A.M., Waberski, D., Harrison, R.A.P., Töpfer-Petersen, E., 2009. Control of bull sperm cell volume during epididymal maturation. Reprod. Fertil. Pev. 21, 469-478.

Santiago-Moreno, J., Toleđano-Díaz, A., Pulido-Pastor, A., Gómez-Brunet, A., López-Sebastián, A., 2006. Birth of live Spanish ibex (Capra pyrenaica hispanica) derived from artificial insemination with epididymal spermatozoa retrieved after death. Theriogenology 66, 283-291.

Soler, A.J., Garde, J.J., 2003. Relationship between the characteristics of epididymal red deer spermatozoa and penetrability into zona-free hamster ova. J. Androl. 24, 393-400.

Soler, A.J., Esteso, M.C., Fernández-Santos, M.R., Garde, J.J., 2005. Characteristics of Iberian red deer (Cervus elaphus hispanicus) spermatozoa cryopreserved after storage at 5 degrees $C$ in the epididymis for several days. Theriogenology 64, 1503-1517.

Songsasen, N., Tong, J., Leibo, S.P., 1998. Birth of live mice derived by in vitro fertilization with spermatozoa retrieved up to twenty-four hours after death. J. Exp. Zool. 280, 189-196. 
Suzuki, K., Nagai, T., 2003. In vitro fertility and motility characteristics of frozen-thawed boar epididymal spermatozoa separated by Percoll. Theriogenology 60, 1481-1494.

Tamayo-Canul, J., Alvarez, M., López-Urueña, E., Nicolas, M., MartinezPastor, F., Anel, E., Anel, L., de Paz, P., 2011. Undiluted or extended storage of ram epididymal spermatozoa as alternatives to refrigerating the whole epididymes. Anim. Reprod. Sci. 126, 76-82.

Yeung, C.H., Barfield, J.P., Cooper, T.G., 2006. Physiological volume regulation by spermatozoa. Mol. Cell. Endocrinol. 250, 98-105. 